\title{
Pattern of availability of non-prescribed medicines and their use as self-medication in Gujarat: a house hold survey
}

\author{
Nazima Yunus Mirza ${ }^{1, *}$, Barna Ganguly ${ }^{2}$ \\ ${ }^{1}$ Associate Professor, ${ }^{2}$ Professor, Dept. of Pharmacology, Pramukhswami Medical College, Karamsad, Gujarat, India
}

*Corresponding Author: Nazima Yunus Mirza

Email: nazimaym@charutarhealth.org

\begin{abstract}
Self-medication is widely practiced everywhere in the world. The drug for self medication has proven efficacy and safety for short-term use in minor illnesses but there is the potential for misuse and abuse of them.

A cross sectional survey was conducted by visiting 800 houses of Anand district of Gujarat. The details regarding self medication were inquired which include the medical conditions for which they used, availability of Fixed Dose Combinations (FDCs), previously prescribed medicines taken as self medication, sources, reference \& reasons for self medication. The Knowledge of the study participants regarding Self medication was inquired by revealing the history of illness in past six months. Ethics Committee approval was taken prior to the study. A total of 501 without prescription medicine formulations were found in $245(30.63 \%)$ houses, more in the urban area (38.25\%) than the rural (23\%). The common conditions for self medication were body ache, arthritis and fever (36.53\%). The commonest source was pharmacy stores whereas family, friends or relatives were commonest sources of information for self medication. The Self decision was taken for $32.93 \%$ of medicines. Total 43 medicines prescribed earlier were used as self medication for other family member including 12 preparations for pediatric use. Only 126 participants had 222 illness episodes in past six month. Of them 18 study respondents self medicated. Half of the respondents were having the knowledge regarding medicine.

There is a need of emphasizing on proper awareness and education related to self-medication.
\end{abstract}

Keywords: Self-medication, Medicines without prescription, Rural, Urban.

\section{Introduction}

Self-medication is an age old practice and a form of self-care. Self-medication can be defined as obtaining and consuming drugs without the advice of physician either for diagnosis, prescription or surveillance of treatment. It is a common practice and internationally has been reported as being on rise and can produce a good result and be a convenient practice for patient. ${ }^{1}$

Although, Over The Counter (OTC) drugs are meant for self-medication and are of proved efficacy and safety, their improper use due to lack in the knowledge of their side effects and interactions could have serious implications, especially in extremes of ages (children and old age) and special physiological conditions like pregnancy and lactation. ${ }^{2}$ The serious health risks in the form of bacterial resistance, dependence, drug withdrawal symptoms, gastrointestinal bleeding, hypersensitivity reactions, increase risk of neoplasia, masking of underlying disease, increase the chances of intoxication etc may occur due to self-medication. ${ }^{3}$ Critiques of self-medication from the medical community have characterized self-care as questionable if not dangerous. ${ }^{4}$ This is becoming a global problem in developing and developed countries and is influenced by several factors such as education, economy of the family and society, law, availability of drugs etc. ${ }^{5}$ The trend in growing public interest in health and health products is driven by easier access to health-related information and by drug advertising. ${ }^{6}$

Many studies were there on self medication practice all over the world. The amount of structured data available on self medication among the population of Gujarat, India is limited. So this study was aimed to get the evidence of self- medication at this region. So this study was aimed to assess the extent of use of self-medication in families of Anand district of Gujarat. The objectives of the study were to identify the pattern of medicines available at home that are not prescribed by Registered Medical Practitioner (RMP), to identify the factors influencing self medication and to assess the knowledge about self-medication.

\section{Materials and Methods}

A cross sectional survey was conducted by visiting 800 houses, equally divided in urban and rural area during the year 2012 to 2014 in Anand district of Gujarat. Sample size was calculated on the basis of prevalence of self medication as per previous study done in India. ${ }^{7}$

One of the family members, of age more than 18 years and capable of giving information of medicine use within the family was selected as study participant and thus were interviewed.

Presence of any health care professional in the family members in visited house or participants who refused to give consent or take part in the study were excluded from the study. Written consent of the participants was taken and confidentiality was maintained.

The structured interview was held in local language. The details regarding the medicines especially about self medication found to be available at home were noted down e.g. the name of medicine, total number of medicines, for whom and for what purpose and amount of medicines took and at what frequent interval, whether for current use or for future purpose etc. Sources of nonprescribed medicines, reference for self medication and reason for self medication were also asked. The drugs were assigned for status as Self 
medication when the use of drugs from modern medicine / alternative medicine system like Ayurveda, homeopathy, hakimi medicine system without consulting qualified health practitioners and/or traditional medicines. Under traditional medicines the use of homemade remedy and treatment obtained by consulting traditional healers were included. The use of diet, holy water, and other non-pharmacological approaches such as massage, exercise, and psychotherapy were not considered as self-medication.

The participants were also inquired of history of illness in past six months, consultation with doctor or use of self medication related to illness. In case of self medication, details related to drug (name, how to use, knowledge of adverse effect, drug-drug interaction, precautions needed) were also inquired.

Data collected for the study included the details of medicines available in the rural and urban houses as:

1. Number of houses having medicines not prescribed by registered medical practitioner

2. Number of formulations available per house

3. Medical conditions for which medicines without prescription taken

4. Availability of Fixed Dose Combinations as Without prescription medicines

5. Previously prescribed medicines Intended for self medication

6. Sources of without prescription medicines

7. Reference for self medication

8. Reason for self medication

9. Knowledge of the study participants regarding Self medication

Ethics Committee approval was taken prior to the study. In the present study the data were subjected to number, percentage and mean as applicable.

\section{Results}

Majority of the participants about $75.38 \%$ were female within the age group of 26 to 55years. The literacy level of the participants in both urban and rural areas $(73.25 \%)$ were at the level of secondary school level and rest (11.13\%) were below primary level.

Majority of participants were from upper middle socioeconomic strata whereas rest $(4.5 \%$ in urban and $18.25 \%$ in rural area) was below these strata.

Out of the total 800 houses visited, $245(30.63 \%)$ houses were found to have medicines without prescription. In urban area significantly more houses $(38.25 \%)$ had medicines without prescription compared to rural area (23\%). A total of 3438 medicine formulations were found in the visited houses, of which without prescription medicine formulations were 501 with an average of 2.05 per house. An average $2.1 \pm 1.62$ and $1.96 \pm 1.95$ medicine formulations were available in urban and rural houses respectively (Table $1)$.

The conditions for which medicines were taken without prescriptions were mainly body ache, arthritis and fever (36.53\%); followed by cough and cold (12.77\%), skin conditions $(12.57 \%)$ and for general wellbeing $(9.5 \%)$ (Table 2).

Majority of the medicines were obtained from pharmacy stores $(76.25 \%)$ followed by relatives $(12.38 \%)$ and friends $(7.19 \%)$ (Table 3$)$.

The commonest sources of information for medicines were previously used medicine in the family, from friends or relatives. Here it was found more in rural based participants $(64.44 \%)$ than that of urban $(58.26 \%)$. The second major (19.76\%) sources of advice were recommendations by the pharmacist. The other less common references for the medicines without prescriptions were previous prescriptions $(7.19 \%)$, media \& internet (4.19\%), and news papers \& magazines (2.99\%) (Table 4).

The various reasons of taking self medications are shown in table 5. Self decision was taken for $32.93 \%$ of medicines whereas 'Doctor's advice not needed for common illness' (16.76\%) and 'previous experience with the disease' (7.19\%) were other common reasons given by the participants (Table 5).

Out of 146 medicine formulations in the form of fixed dose drug combinations, $32.71 \%$ were found from urban area and $22.78 \%$ from rural area. Of them, Non steroidal anti inflammatory medicines (NSAIDs) and Cough and cold preparations were topped the list in rural and urban populations (Fig. 1). Fixed dose combinations of Paracetamol with either ibuprofen, diclofenac, aceclofenac or serratiopeptidase were there in NSAIDs group while cough and cold preparations was in combinations with either antihistamines, paracetamol, mucolytics, dextromethorphan or codeine with 3 to 4 drugs in one preparation. Drugs for gastrointestinal disorders included ranitidine with domperidone and pentoprazole with domperidone.

A total $43(1.46 \%)$ of 2937 medicines prescribed for one family member were intended as self medication for other family member (26 from urban \& 17 from rural area). Twelve preparations intended for pediatric use were also used for other kids at homes without doctor's advice.

The Episodes of illnesses in past six months could be revealed from 126 participants. There were 222 illness episodes in past six months of which, 164 episodes were treated after consultation with the doctor. In 15 episodes they took nothing. Forty three episodes of illness were treated by own. Total 18 study respondents used medicine by themselves during their illness. In urban area, among 10 respondents, paracetamol was used in 10 episodes for the fever, headache, and toothache. Ibuprofen was used in one episode of arthritis and combination of ibuprofen and paracetamol was used for body ache. Ayurvedic medicine was used for skin infection. In rural area among 8 respondents, paracetamol was used in 7 episodes for fever \& headache. Combination of paracetamol with diclofenac was used for arthritis. Ranitidine was used in 3 episodes of acid peptic disorder while cetirizine was used for one episode of headache. Thirteen participants were having the knowledge regarding dose and how long to take medicines and 9 were having the knowledge how to use medicine. None of the 
participants was having any knowledge on drug -drug interaction or adverse effect produced by the medicine.

Table 1: Number of formulations available per house without prescription

\begin{tabular}{|l|c|c|c|}
\hline \multirow{2}{*}{$\begin{array}{c}\text { No. of formulations } \\
\text { without prescriptions }\end{array}$} & \multicolumn{2}{|c|}{ No. of houses } & \multirow{2}{*}{ Total } \\
\cline { 2 - 3 } & Urban & Rural & 245 \\
\hline Total houses $(\mathrm{n}=400$ each) & $153(38.25 \%)$ & $92(23 \%)$ & 501 \\
\hline Total formulations & 321 & 180 & 2.05 \\
\hline Mean \pm SD & $2.1 \pm 1.62$ & $1.96 \pm 1.95$ & \\
\hline
\end{tabular}

Table 2: Medical conditions and use of without prescription medicines

\begin{tabular}{|l|c|c|c|c|}
\hline \multicolumn{1}{|c|}{ Medical Conditions } & $\begin{array}{c}\text { Modern Medicines } \\
\mathbf{n}(\boldsymbol{\%})\end{array}$ & $\begin{array}{c}\text { Ayurvedic } \\
\text { Medicines n }(\%)\end{array}$ & $\begin{array}{c}\text { Herbal \& others } \\
\mathbf{n}(\boldsymbol{\%})\end{array}$ & $\begin{array}{c}\text { Total } \\
\mathbf{n}(\boldsymbol{\%})\end{array}$ \\
\hline Bodyache, arthritis and fever & $177(35.33)$ & $3(0.60)$ & $3(0.60)$ & $183(36.53)$ \\
\hline Cough \& cold & $58(11.57)$ & $3(0.60)$ & $3(0.60)$ & $64(12.77)$ \\
\hline Bronchial Asthma & $4(0.80)$ & $0(0.00)$ & $0(0.00)$ & $4(0.80)$ \\
\hline Skin conditions & $55(10.98)$ & $5(1.00)$ & $3(0.60)$ & $63(12.58)$ \\
\hline Acid Peptic Disease & $27(05.39)$ & $0(0.00)$ & $0(0.00)$ & $27(05.39)$ \\
\hline $\begin{array}{l}\text { Vomiting, diarrhea \& } \\
\text { constipation }\end{array}$ & $16(03.19)$ & $2(0.40)$ & $0(0.00)$ & $18(03.59)$ \\
\hline Digestive purpose & $0(0.00)$ & $9(01.80)$ & $21(04.19)$ & $30(05.99)$ \\
\hline $\begin{array}{l}\text { Other Gastrointestinal } \\
\text { conditions }\end{array}$ & $3(0.60)$ & $4(0.80)$ & $2(0.40)$ & $9(01.80)$ \\
\hline $\begin{array}{l}\text { Gen well being \& } \\
\text { supplements }\end{array}$ & $26(05.19)$ & $15(02.99)$ & $7(01.40)$ & $48(09.58)$ \\
\hline Eye, ear \& nasal conditions & $13(02.59)$ & $1(0.20)$ & $1(0.20)$ & $15(02.99)$ \\
\hline Other conditions & $29(05.79)$ & $5(1.00)$ & $6(1.19)$ & $40(07.98)$ \\
\hline Total & $408(81.44)$ & $47(09.38)$ & $46(09.18)$ & $501(100)$ \\
\hline
\end{tabular}

Table 3: Source of medicine used for self medication

\begin{tabular}{|l|c|c|c|}
\hline \multicolumn{1}{|c|}{ Sources of medicine } & $\begin{array}{c}\text { Urban } \\
\mathbf{n}(\boldsymbol{\%})\end{array}$ & $\begin{array}{c}\text { Rural } \\
\mathbf{n}(\boldsymbol{\%})\end{array}$ & $\begin{array}{c}\text { Total } \\
\mathbf{n}(\boldsymbol{\%})\end{array}$ \\
\hline Pharmacy store & $247(76.95)$ & $135(75.00)$ & $382(76.25)$ \\
\hline Relatives & $37(11.53)$ & $25(13.89)$ & $62(12.38)$ \\
\hline Friends & $26(8.1)$ & $10(5.56)$ & $36(7.19)$ \\
\hline Provision store & $8(2.49)$ & $3(1.67)$ & $11(2.20)$ \\
\hline Patanjali store/Gandhi shop & $1(0.31)$ & $4(2.22)$ & $5(1.00)$ \\
\hline Hakim store & $1(0.31)$ & $0(0)$ & $1(0.20)$ \\
\hline From school & $1(0.31)$ & $0(0)$ & $1(0.20)$ \\
\hline Compounder & $0(0.00)$ & $3(1.67)$ & $3(0.60)$ \\
\hline Total & $321(100)$ & $180(100)$ & $501(100)$ \\
\hline
\end{tabular}

Table 4: Source of information of self-medication for the participants

\begin{tabular}{|c|c|c|c|c|}
\hline Ref. No. & Reference & $\begin{array}{l}\text { Urban } \\
\text { n }(\%)\end{array}$ & $\begin{array}{l}\text { Rural } \\
\text { n }(\%)\end{array}$ & $\begin{array}{l}\text { Total } \\
\text { n }(\%)\end{array}$ \\
\hline 1 & News Paper \& Magazine & $10(3.12)$ & $5(2.78)$ & $15(2.99)$ \\
\hline 2 & Media \& internet & $9(2.80)$ & $12(6.67)$ & $21(4.19)$ \\
\hline 3 & Family, friends or relative & $187(58.26)$ & $116(64.44)$ & $303(60.48)$ \\
\hline 4 & Pharmacist & $65(20.25)$ & $34(18.89)$ & $99(19.76)$ \\
\hline 5 & Previous prescription & $27(8.41)$ & $9(5.00)$ & $36(7.19)$ \\
\hline 6 & Other & $13(4.05)$ & $4(2.22)$ & $17(3.39)$ \\
\hline 2,4 & & $2(0.62)$ & $0(0.00)$ & $2(0.40)$ \\
\hline 3,4 & & $8(2.49)$ & $0(0.00)$ & $8(1.60)$ \\
\hline & Total & $321(100)$ & $180(100)$ & $501(100)$ \\
\hline
\end{tabular}


Table 5: Reasons for self-medication

\begin{tabular}{|l|c|c|c|c|}
\hline $\begin{array}{c}\text { Reason } \\
\text { No. }\end{array}$ & Reasons for SM & $\begin{array}{c}\text { Urban } \\
\mathbf{n}(\boldsymbol{\%})\end{array}$ & $\begin{array}{c}\text { Rural } \\
\mathbf{n}(\boldsymbol{\%})\end{array}$ & $\begin{array}{c}\text { Total } \\
\mathbf{n}(\boldsymbol{\%})\end{array}$ \\
\hline 1 & Doctor's advice not needed for common & $59(18.38)$ & $25(13.89)$ & $84(16.76)$ \\
\hline 2 & illness & $7(2.18)$ & $1(0.56)$ & $8(1.6)$ \\
\hline 3 & Lack of time to visit doctor & $7(2.18)$ & $1(0.56)$ & $8(1.6)$ \\
\hline 4 & Unaffordable doctors fee & $1(0.31)$ & $6(3.33)$ & $7(1.4)$ \\
\hline 5 & Need quick relief & $0(0.00)$ & $1(0.56)$ & $1(0.2)$ \\
\hline 6 & No family support & $1(0.31)$ & $0(0.00)$ & $1(0.2)$ \\
\hline 7 & Lack of trust in medical service & $105(32.71)$ & $60(33.33)$ & $165(32.93)$ \\
\hline 8 & Self decision & $25(7.79)$ & $11(6.11)$ & $36(7.19)$ \\
\hline 9 & Previous experience with disease & $9(2.80)$ & $3(1.67)$ & $12(2.38)$ \\
\hline 10 & Knowledge of disease \& drug & $42(13.08)$ & $40(22.22)$ & $82(16.37)$ \\
\hline 11 & Other & $64(19.94)$ & $32(17.78)$ & $96(19.17)$ \\
\hline 12 & Multiple reasons & $321(100)$ & $180(100)$ & $501(100)$ \\
\hline
\end{tabular}

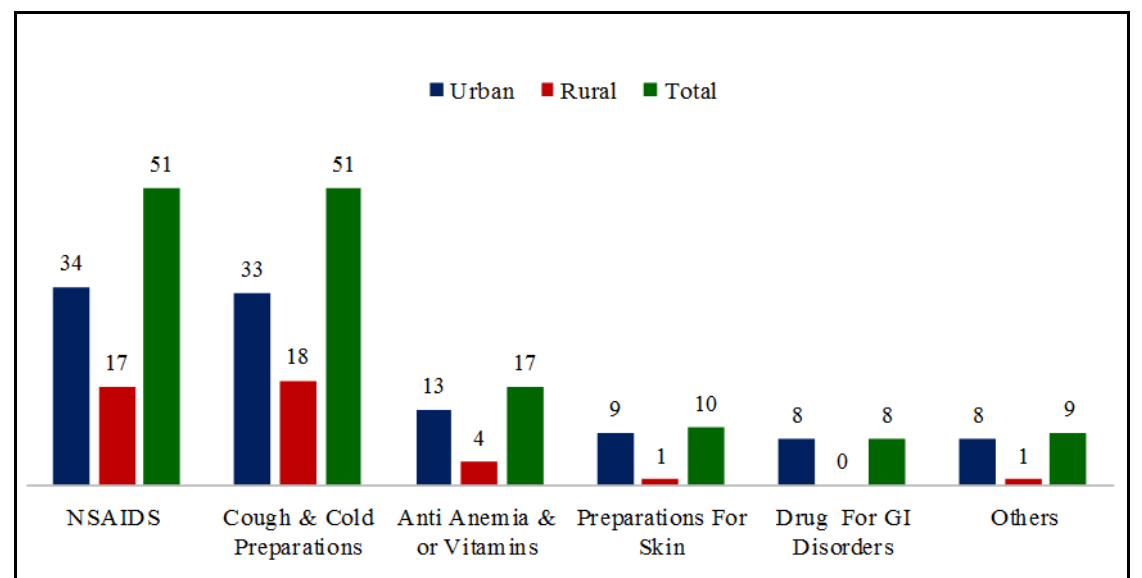

Fig. 1: Number of without prescription medicines as fixed dose combinations

\section{Discussion}

In the international arena it has been observed that there is a trend in change in the treatment of minor ailments through using self-care. Self-medication practice is increasingly recognized throughout the world. The study population in this survey consisted of both urban and rural population. Majority of the respondents were adult.

Self medication for common ailments is widely prevalent in the developing countries. ${ }^{1-2,4-6,8-9}$ The present study revealed that self-medication was practiced for minor and non-serious health complaints like common cold, cough, headache, fever, body aches, indigestion, diarrhea etc. The commonest illnesses that led to self medication in this study (headache, fever, cough and diarrhea) were also reported similarly in rural areas of Pune. ${ }^{10}$

For self medication, major source of medicines found in our study was pharmacy stores $(76.25 \%)$ followed by relatives $(12.38 \%)$ and friends $(7.19 \%)$. The scenario was similar in urban and rural area. Studies from different parts of world also showed the pharmacy stores as major sources of procurement of drugs. ${ }^{2,11,12}$

In this study it was found that $50.48 \%$ of medicines used for self medication were referred by family, friends or relatives out of which $58.26 \%$ in urban and $64.44 \%$ in rural areas. This was followed by pharmacists, previous prescription, media and internet. Our study showed that references of media and internet were higher $(6.67 \%)$ in rural areas than in urban area $(2.8 \%)$ which is a significant finding. A study done by Jain et a ${ }^{13}$ reported the pharmacist as the major source of information in Southern Rajasthan followed by previous prescription. In Haryana, India ${ }^{14}$ the advice given by health care professional followed by friends, family and neighbors and then previous prescription were the major sources of information while in Pune, India ${ }^{15}$ initial doctor's prescription was major source of information for self medication, followed by chemist, advertisement and then neighbor. It was found similar in the studies done at Islamabad Pakistan, ${ }^{16}$ and at Baghdad. ${ }^{17}$ But, Marak A et al at Meghalaya India ${ }^{18}$ found that family member and friends were main as the references for self medication followed by pharmacist and previous prescription.

All studies mentioned above clearly showed that the family members and close friends were the main source of advice on use of self medicated drugs because some of them might experience similar conditions previously. The study showed that there is an influence of other individuals in the 
practice of self medication. This reveals the existence of bad trend in the community where nonprofessionals recommend drug use and needs to be discouraged through public education.

Though less but one of the important and fast spreading information is the role of media, which calls for a rational approach and responsibility while advertising OTC drugs. Strict policy guidelines should be enacted by the Government in this context.

In this study, the criteria of 'self decision' were the major reason for self medication followed by 'Doctor's advice not needed for common illness' and 'previous experience with the disease'. Phadke reported in his study that the economic $(58.5 \%)$ or non availability of health care facility $(29.3 \%)$ were the major reasons for practicing selfmedication at Rural Maharastra. ${ }^{2}$ A study from southern Rajasthan $^{13}$ reported doctor's advice not needed in mild illness as the major reason. $H$. Khan from Islamabad Pakistan $^{16}$ and Ali Jasim from Bagdad $^{17}$ reported the previous experience with the same condition as major reason.

In response to history of episodes of illnesses in past six months, very few participants took the treatment by their own, majority of them consulted doctor and a few of them took home remedy. Paracetamol was found to be the most commonly used drug. A study from an urban area of Delhi ${ }^{19}$ reported with $92.8 \%$ prevalence of self medication by recalling past one month history, in which participants took paracetamol and cough syrups for common cold and fever.

None of the participants had knowledge about drug profile and serious adverse effects which was similar to the study done at Kolkata India ${ }^{20}$ and Rural Maharashtra. ${ }^{2}$ This finding reflects the need of more awareness programs related to proper drug use in both rural as well as urban population.

The current study revealed that the majority of the respondents were unaware of the ADRs and DDI that were possible with the drugs and also do not know the precautionary measures that have to be followed. Drug Controller General of India (DCGI) has provided a list of FDCs that have been banned. Despite this notification some of these banned continue to be marketed in India. ${ }^{21}$ There are both advantages and disadvantages with the use of FDCs. Hence to be useful a FDC should fulfill the guidelines that have been laid down by the WHO for the use of FDCs.

Hence pharmacists have an important role to play in helping people seeking self-medication.

\section{Conclusion}

There is a need of emphasizing on proper awareness and education related to self-medication at the same time the regulators in India needs to clearly define the role of 'over the counter medicines' in the form of separate category which will help promote access to market and will empower consumers who want to take a more active role in their own health care. The doctors and pharmacists can help the community in the form of development of guidelines and recommendation of, over the counter medicines. There remains a major role of health care professionals at all levels right from doctors, pharmacists, and nurses to health care workers in imparting information on use of drugs and some therapeutic advice. ${ }^{22}$

\section{References}

1. Jain S, Malvi R \& Purviya J. Concept of self medication: A review. Int J Pharm Biol Arch. 2011;2(3):831-836.

2. Phalke VD, Phalke DB, Durgawale PM. Self-medication practices in rural Maharashtra. Indian J Community Med. 2006;31(1):34.

3. Galato D, Galafassi LD, Alano GM, Trauthman SC. Responsible self-medication: review of the process of pharmaceutical attendance. Braz J Pharm Sci. 2009;5(4):62533. http://dx.doi.org/10.1590/S1984-82502009000400004.

4. Andualem T. A prospective study on self-medication practices and consumers drug knowledge in addis ababa (Doctoral dissertation, aau). Available from: http://etd.aau.edu.et/bitstream/123456789/597/2/tenaw\%20An dualem.pdf (accessed on 28/12/2011).

5. Sandeep A. Self-Medication: Knowledge and Practice among Urban and Rural Population. Int J Pharm Biol Arch. 2013;4(3):488-492.

6. De-Bolle L, Muhuys E, Andriaens E, Remon J, Bortel LV, Christiaens T. Home medication cabinets and self-medication: A source of potential health threats? Ann Pharmacother. 2008;42:572-579.

7. Shveta S, Jagmohan S: A study of self medication pattern in Punjab. Indian J Pharm Pract. (Association of Pharmaceutical Teachers of India) 2011;4(2):43-46.

8. Hussain A, Khanum A. Self medication among university students of Islamabad, Pakistan- a preliminary study. Southern Med Review 2008;1(1):14-16.

9. Sawalha AF. Descriptive study of self-medication practices among Palestinian medical and nonmedical university students. Res Social Adm Pharm. 2008;4(2):164-172. doi: 10.1016/j.sapharm.2007.04.004.

10. Keche Y. Self medication pattern in rural areas in Pune, India. Int J Med Public Health. 2012;2(4).

11. Solomon Worku, Abebe G Mariam. Practice of Selfmedication in Jimma Town. Ethiop. J. Health Dev. 2003;17(2):111-116.

12. H Khan, S Maheen, GA Alamgeer, A Mahmood, RM Sarfraz, Z Ashraf, M Khalil, MNH Malik. Determinants of Increasing Trend of Self-Medication in a Pakistani Community. Trop J Pharm Res. ISSN: 1596-5996. http://dx.doi.org/10.4314/tjpr.v13i3.19.

13. Jain M, Prakash R, Bapna D, Jain R. Prevalence and pattern of self-medication practices in urban area of southern Rajasthan. Community Med. 2015;6(4):474-477.

14. Jain P, Sachan A, Singla RK, Agrawal P. Statistical study on self medication pattern in Haryana, India. Indo Global J Pharm Sci. 2012;2(1):21-35.

15. Loharkar N. Self Medication Use in Urban Population of Pune, Maharashtra, India. Sch J App Med Sci. 2013;1(6):732-738.

16. H Khan, S Maheen, GA Alamgeer, A Mahmood, RM Sarfraz, Z Ashraf, M Khalil, MNH Malik. Determinants of Increasing Trend of Self-Medication in a Pakistani Community. Trop J Pharm Res. ISSN: 1596-5996. http://dx.doi.org/10.4314/tjpr.v13i3.19

17. Jasim AL, Taqua AF, Salam ST. "Self Medication Practice among Iraqi Patients in Baghdad City." Am J Pharmacol Sci. 2014;2(1):18-23. DOI:10.12691/ajps-2-1-4.

18. Marak A, Borah M, Bhattacharyya H, Talukdar K. A crosssectional study on self-medication practices among the rural population of Meghalaya. Int J Med Sci Public Health. [cited 
February 17, 2016]; Online First: 13 Nov, 2015. doi:10.5455/ijmsph.2016.17072015160.

19. Kumar V, Mangal A, Yadav G, Raut D, Singh S. Prevalence and pattern of self medication practices in an urban area of Delhi, India. Med J DY Patil Univ. [serial online] 2015;8:1620. Available from: http://www.mjdrdypu.org/text.asp?2015/8/1/16/148828.

20. Tejashree T, Sarala N and Girish MB. Evaluation of Self Medication Practices Among Medical and Non Medical Individuals. RJPBCS. 2014; 5(1). ISSN: 0975- 8585.

21. Chugh P, Lhamo Y, 2012. An assessment of vitamin supplements in the Indian market. Indian J Pharm Sci. 74(5):469-473.

22. Bennadi D. Self-medication: A current challenge. J Basic Clin Pharma. 2014;5:19-23.

How to cite this article: Mirza N Y, Ganguly B. Pattern of availability of non-prescribed medicines and their use as self-medication in Gujarat: a house hold survey. Indian J Pharm Pharmacol. 2018;5(4):170-175. 